\title{
MINIMALISMO JUDICIAL: ¿CASS SUNSTEIN EN LA CORTE CONSTITUCIONAL?*
}

\author{
Mario Alberto CAJAS SARRIÁ**
}

\section{INTRODUCCIÓN}

La Corte Constitucional colombiana, en la sentencia C-816 del 30 de agosto de 2004, declaró inconstitucional el acto legislativo 2 de 2003 (estatuto antiterrorista). ${ }^{1}$ En su decisión, la Corte acudió a una práctica de adjudicación denominada minimalismo judicial, ${ }^{2}$ defendida por autores como Cass R. Sunstein. ${ }^{3}$

* Este trabajo tiene como base la ponencia "Minimalismo y adjudicación" presentada en el Congreso Internacional de Filosofía del Derecho, realizado en el Instituto de Investigaciones Jurídicas de la Universidad Nacional Autónoma de México, entre el 28 y el 31 de marzo de 2006. Un análisis similar también ha sido presentado a consideración del comité editorial de la revista Precedente de la Universidad Icesi.

** Licenciado en derecho por la Universidad del Cauca, especialista en derecho público de la Universidad Externado de Colombia, magister en derecho de la Universidad Nacional de Colombia.

1 El estatuto antiterrorista fue promovido por el gobierno del presidente Álvaro Uribe Vélez (2002- 2006, relecto 2006-2010) que cuenta con amplias mayorías parlamentarias.

2 En la sentencia C-816 de 2004, M. P. Córdoba Triviño, Jaime y Uprimny Yepes, Rodrigo, la Corte cita la obra de Sunstein, Cass R., One Case at a Time: Judicial Minimalism on the Supreme Court, Cambridge, Harvard University Press, 1999, pp. 105-144.

3 Sunstein ha publicado obras sobre diversos temas. Entre ellas, The Partial Constitution, 1993; Legal Reasoning and Political Conflict, 1996; Free Markets and Social Justice, 1997; Designing Democracy: What Constitutions Do, 2001; Republic.com, 2001; The Cost-Benefit State, 2002; Punitive Damages: How Juries Decide, 2002; Why Societies Need Dissent, 2003; The Second Bill of Rights, 2004, y Laws of Fear: Beyond the Precautionary Principle, 2005. Algunos de sus trabajos pueden ser consultados libremente en http://www.law.uchicago.edu/faculty/sunstein. 
En este trabajo se presenta la tesis minimalista, defendida por el profesor Sunstein, como una metodología de adjudicación ampliamente practicada por la Corte Suprema de de los Estados Unidos de América cuando interpreta la Constitución. Asimismo, se analiza el modo como la Corte Constitucional Colombiana apropia el minimalismo en un contexto de intenso reformismo constitucional y sobre un tema de amplio impacto jurídico y político.

Este artículo se divide en dos secciones. La primera inicia con una exploración, muy general, sobre el papel que cumple el precedente judicial en la cultura jurídica de los Estados Unidos. Este será el punto de partida para entender el minimalismo judicial que propone Cass R. Sunstein, ${ }^{4}$ con cuyo análisis cierro la primera parte. La segunda se refiere a la reforma de la Constitución en Colombia y su control por la Corte Constitucional. Luego, revisaré cómo la Corte usa el minimalismo judicial en una decisión trascendental de control a la reforma constitucional. Para finalizar, se sugieren otros espacios de ajudicación constitucional en donde podría evidenciarse la práctica minimalista. ${ }^{5}$

4 Cass R. Sunstein es uno de los más notables juristas estadounidenses. Es profesor de la Facultad de Derecho y del Departamento de Ciencia Política en la Universidad de Chicago. Uno de los primeros trabajos en donde el autor analiza el minimalismo es "Incompletely theorized agreements", Harvard Law Review, vol. 108, 1995. Véase también: Legal Reasoning and Political Conflict, Oxford, Oxford University Press, 1996. El minimalismo aparece más desarrollado en One Case at a Time: Judicial Minimalism on the Supreme Court, publicado en 1999 (texto que cita la Corte Constitucional colombiana en la sentencia C-816 de 2004), y Radicals in Robes: Why Extreme Right - Wing Courts Are Wrong for America, 2005. Los más recientes escritos sobre el tema son dos artículos de febrero de 2006: Problems with minimalism y Burkean Minimalism, http:/ssrn.com/ abstract_id $=880144$ y http:/ssrn.com/abstract_id $=880121$.

5 Là obra constitucional de Sunstein es principalmente citada por la Corte Constitucional, pero también algunos autores colombianos se refieren a sus trabajos, como López Diego Eduardo, El derecho de los jueces, Bogotá, Legis, 2006; Uprimny, Rodrigo y Fuentes, Adriana, Libertad de prensa y derechos fundamentales: análisis de la jurisprudencia constitucional en Colombia (1992-2005), Bogotá, De justicia-Andiarios, Fundación Konrad Adenauer, 2006, p. XX. Everaldo Lamprea M. se refiere a los aportes teóricos de Sunstein sobre el análisis económico del derecho, en materia del debate sobre regulación y desregulación: "Los servicios públicos domiciliarios y el Estado regulador", Precedente, Anuario Jurídico, 2004, Cali, y "Derechos fundamentales y Consecuencias Económicas", Revista de Economía Institucional, Bogotá, vol. 8, núm. 12, primer semestre de 2006. 


\section{El PRECEDENTE JUDiCIAL EN LOS ESTADOS UNIDOS DE AMÉRICA}

Para comprender plenamente el minimalismo judicial, como aparece formulado en la obra del profesor Cass R. Sunstein, es necesario conocer la cultura jurídica estadounidense. Ese análisis desborda ampliamente el propósito de presente trabajo, pero, de manera general, es importante tener en cuenta aspectos como el papel central que cumplen los jueces - en especial la Corte Suprema - en la interpretación de la Constitución americana, y la manera como sus decisiones van moldeando el derecho constitucional estadounidense. ${ }^{6}$ Los puntos de vista de la Corte acerca de lo que significa la Constitución en los casos que son sometidos a su jurisdicción - en un sistema difuso de control constitucional - pueden cambiar: sus lecturas pueden llevar a "correcciones" de planteamientos o decisiones previas. Aspectos como el contexto político en el que se encuentre la Corte en un periodo determinado en el tiempo, condiciones sociales o económicas pueden hacer necesario que se produzcan cambios en la interpretación y por lo tanto en su jurisprudencia. ${ }^{7}$ Estos cambios se aprecian en los fallos y deben analizarse con respecto la fuerza del precedente de la Corte Suprema de los Estados Unidos, el más importante tribunal federal del país, en donde coexisten dos sistemas judiciales: el estatal y el federal (o nacional).

El principio del stare decisis o "estarse a lo decidido" tiene que ver con la sujeción de los jueces a los fallos previos o la decisión presente que gobierna los casos similares o análogos en el futuro. El precedente puede vincular al juez frente a sus propios fallos (precedente horizontal) o a los jueces inferiores en jerarquía con respecto a los fallos que sobre casos análogos hayan proferido sus jueces superiores en jerarquía (precedente vertical). Esto obliga a seguir reglas o subreglas fijadas en los fallos, que en el caso del precedente vertical pueden tener —en la práctica- efectos generales por vía de la interpretación que hacen los jueces,

6 Para una visión más amplia sobre el control judicial de la Constitución en los países anglófonos, véase Tushnet, Mark, "Judicial Review of Legislation", en Cane, Peter et al., The Oxford Handbook of Legal Studies, Nueva York, Oxford University Press, 2003.

7 Algunos de los cambios más notables en la jurisprudencia constitucional estadounidense se presentan en periodos como durante la Gran Depresión y el New Deal de Roosevelt, la Guerra Civil de Secesión o en la lucha por los derechos civiles y en contra de la segregación racial. Al respecto véase Tribe, Lawrence, American Constitucional Law, 3a. ed., Nueva York, Foundation Press, 2000, vol. 1, p. 78. 
más allá de los efectos concretos o inter partes de la decisión del juez. ${ }^{8}$ De manera muy general, se puede afirmar que la aplicación o no de un precedente dependerá, entre otros factores, de las similitudes y las diferencias fácticas que existen entre el caso a resolver y el caso que dio lugar al precedente. Esto requiere experticia sobre el modo como se analizan los hechos de un caso frente a otro. Es necesario valorar si aquellos que fueron evaluados y produjeron un fallo son análogos o no frente a los que se deben decidir en el nuevo caso. El juez, una vez que valora esas semejanzas y diferencias, puede decidir: ${ }^{9}$

1. Aplicar (apply) la regla del precedente cuando se trate de dos litigios verdaderamente similares.

2. Seguir (follow) la regla del precedente cuando a pesar de que existen diferencias relevantes entre los dos casos, a juicio del tribunal, éstas no justifican un trato jurídico distinto y, por tanto, extiende, a través del razonamiento analógico, la regla del precedente al nuevo supuesto.

3. Distinguir (distinguish) esto es, no aplicarla en el asunto que resuelve y crear una nueva regla, cuando a criterio del tribunal las diferencias entre ambos casos son significativas y merecen un trato jurídico distinto.

El contraste entre casos va definiendo los contornos normativos de un precedente. Los juristas americanos insisten en que el valor normativo de un precedente es indeterminado hasta que no se aplique, extienda o distinga en litigios posteriores. Existen problemas al determinar la regla que establece un precedente y en la formulación del juicio de igualdad entre los casos que se contrastan. Por esto, cuando menos, hay dos posturas sobre el modo como los precedentes horizontales vinculan a los jueces en los Estados Unidos: la primera de ellas, una doctrina del precedente que puede llamarse "maximalista" y según la cual la regla de un caso fallado

8 Sobre la obligatoriedad del precedente judicial, en Colombia, véase López Medina, Diego Eduardo, El derecho de los jueces, 2a. ed., Bogotá, Legis, 2006; Bernal Pulido, Carlos, El derecho de los derechos, Bogotá, Universidad Externado de Colombia, 2005. Para una visión comparada sobre el tema, véase MacCormick, Neil y Summers, Robert (eds.), Interpreting Precedents. A comparative Study, USA, UK, Ashgate-Darthmouth, 1997.

9 Cfr. Magaloni K., Ana Laura, El precedente constitucional en el sistema judicial norteamericano, Madrid, McGraw-Hill, 2001, pp. 83 y 84 . 
que vincula a un juez en otro caso análogo debe ser tan abstracta y general, que puede abarcar una tipología amplia de asuntos para que ese caso resuelto signifique una individualización de esa regla, frente a múltiples opciones posibles. De otro lado, según la postura "minimalista", la regla de un precedente se debe fijar de manera completa, con un ámbito normativo limitado, de modo tal que el caso resuelto sólo gobierne circunstancias fácticas análogas a ese caso concreto. Detrás del debate entre ambas posturas está el problema de los límites y la legitimidad del poder de crear derecho que tienen los jueces, pues el alcance de un precedente determina qué tanto se colma el derecho prexistente. ${ }^{10}$

\section{El minimalismo de Sunstein}

Una vez formulado, de manera muy general, el papel que cumple el precedente judicial en la cultura jurídica americana, es posible comprender la posición que Cass R. Sunstein adopta en defensa del minimalismo judicial, una práctica de la adjudicación, que él afirma, se encuentra presente en el modo como la Corte Suprema de los Estados Unidos decide diversos temas.

10 Sobre la jurisprudencia de la Corte Constitucional colombiana, coincido con el planteamiento de Rodrigo Uprimny y Adriana Fuentes: "No pretendemos resolver esta difícil controversia entre los defensores de posturas maximalistas a nivel teórico, como Dworkin o Bockendorfe, o minimalistas, como aquellas de Sunstein. Según nuestro criterio eso no es necesario... en el estado actual del desarrollo de la jurisprudencia colombiana, y al menos para el análisis académico del trabajo de la jurisprudencia en derechos fundamentales, estas dos perspectivas deben ser consideradas como complementarias y no contradictorias. Así, es indudable que los tribunales, y en especial la Corte Constitucional, han logrado, a pesar de los desacuerdos filosóficos de sus integrantes, consensos metodológicos y teóricos de baja abstracción para resolver casos y elaborar líneas jurisprudenciales: pero igualmente es lícito suponer que las diferentes líneas jurisprudenciales pueden expresar, en forma discreta y muchas veces tácita, opciones filosóficas y políticas. Por ello el análisis académico del trabajo de la Corte debe intentar revelar y criticar esas preferencias ideológicas. En consecuencia, creemos que el estudio jurisprudencial debe no sólo describir las categorías dogmáticas, las subreglas y las líneas jurisprudenciales, sino que debe intentar descubrir la o las filosofía (s) constitucional (es) implícita (s) a esa práctica jurídica, cuando ello aparezca posible y fecundo". Cfr. Libertad de prensa $y$ derechos fundamentales: análisis de la jurisprudencia constitucional en Colombia (1992-2005), Bogotá, Dejusticia-Andiarios-Fundación Konrad Adenauer, 2006, pp. XX y XXI. 
Para comenzar, Sunstein considera que la Constitución de los Estados Unidos tiene contenidos abiertos y abstractos acerca de las más altas aspiraciones de la sociedad. Así, por ejemplo, la Constitución plantea entre otros éstos interrogantes relacionados con la libertad o la igualdad: ¿cuándo el Estado realmente discrimina por razones de raza o por la orientación sexual?, o si el Estado restringe la libertad de expresión cuando regula los costos de las campañas; controla Internet o cuando regula programas educativos para los niños, o el tiempo gratuito al aire que deben tener los candidatos en los medios de comunicación. Algunas veces la Corte Suprema responde a estas preguntas en sus fallos, pero usualmente los jueces deciden muy poco, dejan aspectos abiertos. Sobre la libertad o la igualdad, de manera deliberada, deciden sobre lo que debería dejarse sin decir. Esta es una práctica extendida pues los jueces hacen y dicen tan poco como sea necesario en orden a justificar el resultado. ${ }^{11}$ Por todo esto, Sunstein afirma: "El minimalismo constitucional ha sido la característica más destacada del derecho americano en la década de los noventa". ${ }^{12}$ El minimalismo judicial consiste entonces en decir lo menos posible para justificar la decisión, en dejar sin decidir lo que más se pueda.

El minimalismo no responde a una teoría elaborada por los jueces, ni es un programa determinado, sino que corresponde al comportamiento de los jueces al decidir, de manera real, los casos. El autor defiende su posición a favor del minimalismo, al menos por estas razones: ${ }^{13}$

1. Esta práctica permite que las Cortes respeten sus precedentes al considerar casos sobre los cuales se puede realmente decidir, mediante un "uso constructivo del silencio". ${ }^{14}$

2. Se reducen los ámbitos de la decisión a un caso concreto, se dejan espacios abiertos y de esta forma permite que se tomen decisiones sin entrar a considerar aspectos en donde no se lograrían acuerdos entre los jueces colegiados de un tribunal, o más aún cuando es imposible

11 Cfr. Sunstein, Cass R., One Case at a Time: Judicial Minimalism on the Supreme Court, 2a. ed., Cambridge, Harvard University Press, 2001, p. 3.

12 Ibidem, p. 3.

13 Ibidem, pp. 5-7.

14 Este uso consistiría en no pronunciarse sobre aspectos de difícil consenso entre jueces colegiados. 
que un juez constitucional obtenga la información necesaria, que incluso no estaría disponible para otros actores políticos o jurídicos.

3. Hace menos frecuentes los errores judiciales y menos perjudiciales sus efectos, pues es muy difícil prever las consecuencias futuras de un fallo.

4. Favorece la democracia deliberativa al permitir un debate amplio en todos los niveles. Cuando hay división sobre lo que significa la moral, es mejor deliberar en otros espacios, a que un juez tome una decisión al respecto. ${ }^{15}$

Sunstein sostiene que se pueden identificar cuatro grupos principales de intérpretes de la Constitución estadounidense: 16

1. Los originalistas: argumentan que la Corte debe reivindicar el sentido real que los redactores del texto constitucional sentaron al crear la carta. Los principales defensores son Antonin Scalia y Clarence Thomas, ambos magistrados de la Corte Suprema. ${ }^{17}$

2. Un segundo grupo propone que se debe evitar la discusión moral y política, acudiendo a la historia. Se trata de favorecer la regla de la mayoría. La Corte Suprema no debe invadir la esfera sagrada del Congreso. El defensor principal de esta tendencia es el magistrado Rehnquist. ${ }^{18}$

3. Un tercer grupo plantea que la Corte debe tener juicios independientes para interpretar la Constitución. A este grupo pertenecería, por ejemplo, Ronald Dworkin, cuando propone que un caso es inconstitucional

15 La construcción de una verdadera democracia deliberativa es una preocupación central en la obra de Sunstein. Algunos de sus trabajos al respecto están disponibles en español: "Sustituir unos riesgos de salud por otros", en Elster, John (comp.), La democracia deliberativa, Gedisa, 2001, y "Más allá del resurgimiento republicano", en Gargarella, Roberto et al. (comps.), Nuevas ideas republicanas: autogobierno y libertad, Paidós, 2004.

16 Las dos posturas también defienden un modo de establecer la ratio decidendi de una sentencia. El método planteado por el profesor A. Goodhart sería el prototipo minimalista, mientras que el método maximalista estaría representado, entre otros, por $\mathrm{F}$. Shauer.

17 Cfr. Cass R., Sunstein, Radicals in robes: Why extreme Right- Whing are wrong for América, Cambridge, Basic Books, 2005.

18 William H. Rehnquist llegó a la Corte Suprema en 1971 y la presidió desde 1986. $\mathrm{Su}$ postura es "conocida por su compromiso con la restricción judicial y el mayoritarismo... [refleja] una construcción restringida de los derechos constitucionales", en Geofrey Stone, Louis et al., Constitutional Law, 5a. ed., Nueva York, Aspen, 2005, LXXIII. 
cuando no cumple con la integridad expresada en principios y valores. También Richard Epstein, cuando se refiere a la protección de los derechos de propiedad privada.

4. Otro grupo propone que el rol de la Corte debe ser la promoción del carácter democrático del proceso de debate público. Debe proteger condiciones para la democracia, por ejemplo, garantizando a los grupos el adecuado acceso al debate democrático.

Según Sunstein, la Corte Suprema no ha seguido al pie de la letra ninguna de estas teorías, y tampoco es posible identificar alguna regla sobre la manera como se ha decidido un caso, en donde se pueda "etiquetar" a un magistrado con una doctrina específica, durante todo su desempeño como juez, aunque, por ejemplo, en algunos de sus pronunciamientos defiendan una postura que uno podría asociar con una doctrina en particular.

Una profunda preocupación de Sunstein es la "derechización" de los jueces federales estadounidenses. Esto lo analiza en uno de sus trabajos más recientes: Radicals in Robes: Why extreme Right-Whing are wrong for América. Para eso utiliza sus anteriores aportes sobre el minimalismo con el fin de desnudar las posiciones que imprimen un sello ideológico y partidista a las decisiones de los jueces de la Corte Suprema. ${ }^{19}$ Estas posturas están representadas en cuatro diferentes aproximaciones interpretativas a la Constitución americana:

La perfeccionista, que pretende que la Constitución sea lo mejor que ella pueda ser. Sus seguidores piensan que el texto dice todo aquello que sus aspiraciones esperan de él. Ha sido clave en las decisiones liberales de la Corte. Un ejemplo sería la Corte del juez Earl Warren cuando decidió sobre la segregación racial. ${ }^{20}$ Consideran que la Constitución reconoce o crea nuevos derechos de alguna manera. Si creen en algún derecho que debe ser reconocido, entonces consideran que la Corte Suprema debe decir que ese derecho hace parte de la Constitución. A manera de ejem-

19 Cfr. Sunstein, Cass R., Radicals in Robes: Why extreme Right- Whing are wrong for América, Cambridge, Basic Books, 2005, pp. XII y XIII.

20 Se refiere a Earl Warren, quien presidió la Corte Suprema americana en la década de los sesenta. Algunos definen su postura como "segura e intuitivamente fundada en el juego limpio y la justicia fundamental"; Cfr. Geofrey Stone, Louis M. Seidman et al., Constitutional Law, cit., nota 18, LXXIX. 
plo, Sunstein incluye en esta concepción a Ronald Dworkin, de quien afirma:

es uno de los principales filósofos del siglo veinte (y del 21 también) no usa la expresión-[perfeccionismo] pero él ve el perfeccionismo, según yo lo entiendo, como una parte esencial de la interpretación jurídica. Según su postura, la interpretación legal es una forma de situar los materiales legales existentes en su "mejor luz constructiva", o hacer de ellos lo mejor que se pueda. Dworkin acepta que los jueces están obligados a "hacer coincidir" el derecho existente, los jueces le deben ser fieles, ellos no pueden legítimamente poner el derecho por fuera de su ropaje... Pero si el derecho existente tiene ambigüedades o deja interrogantes, los jueces deben tratar de hacer lo mejor posible. Suponga, por ejemplo, que la Corte está decidiendo si la Constitución protege el derecho al suicidio asistido (eutanasia): Dworkin cree que los jueces deben identificar los principios más relevantes que puedan traerse desde las decisiones previas de la Corte respecto al contenido de la "libertad", y también preguntarse cuáles de estos principios protegen el derecho al suicidio asistido. $^{21}$

La segunda aproximación es la mayoritaria o "mayoritarista". Ésta pretende que la Constitución promueva la democracia y, por eso, que la Corte Suprema debería dejar las mayores decisiones al órgano representativo. Oliver Wendell Holmes ${ }^{22}$ se clasificaría dentro de esta tendencia. Hoy, dice Sunstein, es difícil encontrar a algún magistrado de la Corte que defienda esta postura.

El tercer punto de vista es el minimalismo. Quienes lo practican son magistrados escépticos sobre las teorías generales cuando se debe interpretar para decidir. Ellos prefieren decidir caso por caso; afirman que la Constitución no está congelada en el tiempo, pero a la vez temen a un amplio ejercicio del Poder Judicial. Están en desacuerdo con quienes consideran que la Corte debe crear nuevos derechos y libertades partien-

21 Scalia es uno de los magistrados que integran la Corte actual. Su postura es caracterizada como conservadora por su "fuerte oposición a los test, al balanceo constitucional y a las interpretaciones no textuales". El magistrado Thomas es el segundo afroamericano en llegar a la Corte (1991) y es considerado por algunos autores como "decidido a sentar precedentes en favor de su comprensión acerca de lo que es el texto de la Constitución"; Cfr. Stone, Geofrey et al., Constitutional Law, cit., nota 18, p. LXXIII.

22 Cfr. Radicals in Robes: Why extreme Right-Whing are wrong for América, Cambridge, Basic Books, 2005, p. 32. 
do de las tradiciones y prácticas fundacionales. Prefieren la estrechez en las decisiones más que su amplitud. Esta postura es la defendida por Sunstein, quien afirma que la tendencia fue representada en el pasado por el magistrado Frankfurter, y en la Corte de hoy por la magistrada Sandra Day-O'Connor. ${ }^{23}$

Finalmente, se encuentran los fundamentalistas. Para ellos la Constitución se debe interpretar en su sentido original, tal como ésta se ratificó. Así, por ejemplo, si la Constitución no prohíbe la discriminación racial, ésta se permite; si no prohíbe el trabajo infantil, debe permitirse. Este grupo es el denominado radical porque niega las otras tres aproximaciones sobre la Constitución. Son excluyentes, representan casi que un "credo constitucional". Según opina Sunstein, el Partido Republicano defiende esta tendencia e incluso ha intentado una repudiable presión a los jueces, como en el caso de Terri Schiavo, ${ }^{24}$ para que acojan su plataforma ideológica. Ellos consideran que la Constitución refleja únicamente su ideología. Esta concepción habría sido promovida por el presidente Reagan y por los dos presidentes Bush, quienes han nominado jueces y magistrados conservadores y jóvenes, para perpetuar la ideología. Esta postura pretende devolver la Constitución al siglo XIX. En los últimos 20 años, los lideres republicanos han construido una agenda para el Poder Judicial federal, que al menos incluye: reducir el poder del gobierno federal, incluso el del Congreso; disminuir los derechos de los acusados por delitos; invalidar los programas de acción afirmativa; eliminar leyes sobre financiamiento electoral; intervenir los derechos individuales a la privacidad — por ejemplo restringiendo el aborto_-; restar valor a la Constitución para dejar por fuera del control democrático a los derechos de propiedad; prohibir al Congreso que regule el medio ambiente; proteger

23 Su filosofía judicial fue caracterizada por el escepticismo, particularismo y pragmatismo. Él no creía que las reglas generales con contenidos valorativos en casos particulares, pudieran ser defendidas de manera objetiva; Cfr. Stone, Geofrey et al., Constitutional Law, cit., nota 18, p. LXIX

24 Felix Frankfurter, antes de ser postulado por el presidente Roosevelt a la Corte Suprema, sirvió como su asesor en algunos aspectos de la formulación del New Deal. Durante su ejercicio en la Corte, mostró una gran preocupación por la legitimidad del control judicial y de la "autorestricción" de los jueces. De otro lado, la magistrada Sandra Day-O'Connor es la primera mujer en llegar a la Corte Suprema. Fue postulada por el presidente Reagan en 1980, es caracterizada por preferir el "balanceo" respecto a la interpretación constitucional y el particularismo - fallar "caso por caso"-; cfr. Stone, Geofrey et al., Constitutional Law, cit., nota 18, pp. LXXII y LXXIII. 
intereses comerciales e incluso dejar por fuera de la regulación del Estado la publicidad comercial.

Según el autor, en la Corte Suprema de hoy no es posible hablar de una presencia de izquierda o liberal, sino más bien de posturas de derecha y centro. Por ejemplo, los magistrados Thurgood Marshall ${ }^{25}$ y Brennan, ${ }^{26}$ liberales de la década de los ochenta y quienes actuaban en favor de grupos desaventajados o de los pobres, hoy han sido sustituidos por conservadores — quienes por aquella época eran la minoría-. Así, los fallos se decidan por cinco votos a favor y cuatro en contra, o por seis votos a favor y tres en contra, la Corte se ha derechizado. Hay una clara intención de revertir fallos como Roe vs. Wade sobre aborto y Miranda vs. Arizona sobre debido proceso, con el fin de recuperar la "Constitución perdida" (que sería la de 1932). Frente a esto, Sunstein considera que el minimalismo es una opción correcta, neutral ante grupos que compiten. Los minimalistas dan pequeños pasos porque evitan equivocarse. Los grandes avances han implicado primero caminos minimalistas, en especial en materia del núcleo o corazón ${ }^{27}$ de los derechos, como en el caso de la prohibición de la segregación racial que inicialmente se hizo mediante reglas no muy amplias. ${ }^{28}$

En el minimalismo judicial estadounidense se decide caso por caso, no hay grandes teorías. Y cuando se decide caso por caso no es posible establecer reglas generales; hay reglas pero sobre el caso específico. Por

25 Se refiere al dramático caso de la mujer estadounidense que se encontraba en coma y que generó un agudo debate moral, jurídico y político sobre la decisión de su ex esposo, en tensión con la familia de la mujer, sobre la interrupción de la alimentación asistida. La controversia duró hasta 2005, cuando se decidió a favor de esta última opción.

26 Fue el primer afroamericano en llegar a la Corte Suprema, postulado por el presidente Lyndon Jonson en 1967. Su actividad en defensa de los derechos civiles, la igualdad racial y la lucha por los derechos de las minorías, dejó una honda huella en la historia jurídica americana. Como magistrado, defendió a las minorías, se caracterizó por su interpretación progresista acerca de derechos como la libertad de prensa y la libertad de expresión; cfr. Stone, Geofrey et al., Constitutional Law, cit., nota 18, p. LXXIII.

27 William J. Brennan J., fue postulado por el presidente Eisenhower en 1952. Fue un magistrado progresista ("liberal") y sus posturas defendieron la libertad de expresión, el debido proceso en materia penal, entre otros; $c f r$. Stone, Geofrey et al., Constitutional Law, cit., nota 18, p. LXIII.

28 El autor se refiere a la expresión inglesa core, que en una traducción libre entiendo por núcleo. 
ejemplo, si en un caso se fija una regla específica con respecto al tratamiento de una persona discriminada por su discapacidad mental, ésta regla no se amplía el tratamiento de una persona discriminada por razones de raza o étnicas. La Corte Suprema usualmente llega a "acuerdos carentes de una teoría completa", es decir consensos sobre lo específico, pero no sobre lo abstracto. No se crean definiciones aunque sí principios aplicables por analogía a los casos concretos: recurren a la formulación de un test para determinar casos de discriminación. Un test adopta el "standard" de lo razonable pero no exactamente el grado de razonabilidad que requiere un caso particular. ${ }^{29}$ Sunstein sostiene que hay casos con aspectos sobre los cuales es difícil lograr un acuerdo y que por ello es mejor dejarlos a un lado y decidir sobre lo demás: es decir sobre aquello que sí permite llegar a un acuerdo. En el stare decisis un pronunciamiento de la Corte Suprema es difícil de modificar, por eso, en caso de error sus efectos son más perjudiciales: $v$. gr., en materia del derecho a la libertad, una decisión que fije una regla general, amplia, para proteger el derecho en ese caso concreto, puede llegar a conculcar el mismo derecho en ocasiones posteriores, si se aplica la regla general que se fijó en la decisión previa. El autor también se refiere al "certiorari" en donde la Corte Suprema decide si toma o no un caso y no está obligada a justificar por qué rechaza su conocimiento. Los jueces de la Corte están de acuerdo en rechazar el conocimiento del caso, pero no sobre las razones para haberlo hecho. Esto ocurre en la Corte Suprema, usualmente, cuando la decisión genera amplios desacuerdos y por eso sería una forma de minimalismo. ${ }^{30}$

Sunstein advierte que uno de los problemas generados por las decisiones amplias y profundas — como en el caso de Roe vs. Wade —31 es que se decide previamente y esto "amarra" fallos posteriores. Pero también afirma que en la práctica un análisis de la jurisprudencia norteamericana muestra cómo el maximalismo no "amarra" tanto como quisieran o pensaban aquellos jueces que han tomado este tipo de decisiones. Incluso, algunas Cortes posteriores pueden ver esos fallos anteriores como meros "dicta", por ser amplios y profundos, y de esta manera apartarse de la decisión anterior al no encontrar que ese precedente sea vinculante. El juez

29 Sunstein, Cass R., One Case at a Time: Judicial Minimalism on the Supreme Court, cit., nota 2, p. 12.

30 Al respecto véase el apartado II.2 de este mismo trabajo.

31 Se refiere al fallo de la Corte Suprema de Estados Unidos de 1973, que permite la práctica del aborto en circunstancias específicas. 
minimalista falla el caso que tiene a la mano. Por el contrario, una Corte como la del New Deal ${ }^{32}$ fue maximalista. Contrario a lo que generalmente se piensa acerca del precedente en el common law, no se crean grandes reglas abstractas que gobiernen casos futuros más amplios, sino reglas específicas para los casos concretos. Sin embargo, una decisión minimalista puede ser ampliada por una Corte posterior convirtiendo en maximalista lo que inicialmente no se había construido con tal propósito de generalidad o extensión. El maximalismo crea un peligro adicional y es que el Congreso no aborde por la vía legal la discusión de los temas porque la Corte ha cerrado el debate al señalarle límites muy estrechos para su actuación. Esto impediría la discusión y decisión democráticas. Para Sunstein, se ha comprobado que incluso las sociedades y el público en general tienden a ser minimalistas: todos damos pasos cortos.

El minimalismo también requiere que se supere la distinción entre $r u$ les y standards (o principios y valores a la manera de Dworkin). Esta metodología requiere en gran medida el uso de la analogía. Un juez que falla caso por caso flexibiliza pequeños acuerdos. Como en las democracias hay un límite para decidir, lo pequeños acuerdos prevalecen frente a las grandes teorías. Los acuerdos carentes de una teoría completa hacen que se busquen similitudes entre los casos y esto evita el debate judicial. Esta práctica es muy ventajosa: no crear reglas muy generales facilita la analogía para lograr esos acuerdos y en el futuro puede "distinguirse" el precedente con el fin de corregir errores.

En general, a lo largo de la obra de Sunstein, se aprecia un marcado interés sobre los efectos que puedan causar las decisiones muy amplias o que lleven a una petrificación de la adjudicación en temas considerados "sensibles", más que una preocupación por los desacuerdos entre los miembros de una Corte. Es así como, en síntesis, recomienda el método minimalista cuando:

1. Debe hacerse para evitar anacronismos que se producen con el cambio de los valores sociales. Sin embargo, cuando las reglas del mercado deben ser claras o para que los actores hagan planes, el minimalismo puede incrementar los costos de decisión.

32 Así se denominó el amplio programa de reformas sociales impulsadas durante la administración del presidente Franklyn Delano Roosevelt. 
2. Favorece una sociedad libre que requiere un pluralismo razonable y por lo tanto desacuerdos sobre muchos aspectos.

3. Permite que cada cual opere desde sus opiniones y llegue a ciertos consensos. El minimalismo pretende estabilidad, con cierta reciprocidad, junto al respeto mutuo. Las "teorías incompletas" de los jueces animan a la gente a vivir junta a pesar de los fuertes desacuerdos y promueve que los cambios provengan de la gente, de su verdadero compromiso. El minimalismo se puede parecer al liberalismo político, aunque no en el sentido estricto de aquel defendido por John Rawls: uno de los principales objetivos de Rawls es promover grandes debates filosóficos entre los actores de la vida política, mientras que el minimalismo empodera a los actores al debate público.

4. Los resultados de una decisión pueden ser inesperados. Decidir caso por caso puede reducir los costos de estos errores en el futuro. Prever el impacto de una decisión es difícil, incluso en sistemas interconectados: por ejemplo en ciencia, economía o política.

5. Cuando los jueces se hallan en casos en donde están en el centro o la mitad factual o moral, o bien hay incertidumbres o una variabilidad prevista. ${ }^{33} \mathrm{O}$ cuando la decisión puede ser confusa frente a casos futuros.

6. Cuando una decisión no exija una planeación.

7. La regla no promoverá las condiciones democráticas.

De otra parte, no se aconseja el minimalismo como práctica judicial, cuando:

1. Un juez tiene claridad sobre las reglas profundas y amplias que va a fijar.

33 En realidad, Sunstein hace referencia a los llamados casos difíciles de Ronald Dworkin. Para una mayor información sobre las influyentes propuestas de Dworkin sobre los derechos fundamentales y la interpretación jurídica, véase, entre otros, en castellano: La decisión judicial: el debate Hart- Dworkin, estudio preliminar de César Rodríguez, Universidad de los Andes, Siglo del Hombre Editores, 1997; en inglés sus obras ya clásicas: Taking Rights Seriously, Harvard University Press, 1977, la traducción castellana Los derechos en serio, Ariel, Law's Empire, Harvard University Press, 1986, traducción castellana El imperio del derecho, Gedisa. Algunos de sus escritos recientes pueden ser consultados libremente: http://philosophy.fas.nyu.edu/object/ronalddworkin. 
2. Si no se fija una regla clara, los jueces inferiores van a decidir con mayor libertad y tal vez puedan errar más fácil.

3. El juez colegiado tiene una confianza considerable en la solidez de su decisión, debe procurar reglas amplias.

4. La decisión del juez reduce los costos e incertidumbre futuros de los abogados litigantes y de los jueces.

5. La planeación futura es importante. Allí se debe optar por el maximalismo.

6. La decisión sí promoverá condiciones democráticas.

Un juez puede ser conservador para dejar intacta una tradición, como un tribunal liberal puede también ser minimalista para dejar el núcleo o core de derechos. Incluso, en reglas de gobierno o de justicia (parte orgánica o dogmática de la Constitución) puede haber minimalismo, aunque esta práctica pueda apreciarse de manera más explícita en casos que comprometen reglas de justicia (parte dogmática). De hecho, habría unos "diez acuerdos generales" en materia de derechos en los Estados Unidos, pero esto no implica el consenso total. Se podría decir que existen acuerdos sobre un núcleo esencial, pero las zonas oscuras estarían sujetas al minimalismo. Los derechos se van creando y ese core o corazón de los principios va cambiando.

\section{Reformismo constitucional y control judicial}

La Constitución de 1991 encargó a la Corte Constitucional la función de guardar la integridad y la supremacía de la Constitución, y la erigió en el máximo intérprete de los derechos fundamentales. La Corte ha desarrollado ampliamente la carta política, superando el textualismo ha recurrido a nuevas formas de ver el derecho y creado un nuevo constitucionalismo colombiano, con la promoción y garantía de los derechos fundamentales -incluidos los derechos económicos, sociales y culturales- - Su activismo judicial convierte a la Corte Constitucional, sin lugar a dudas, en protagonista de la vida jurídica — $-\mathrm{y}$ también política- del país en los últimos quince años.

El Congreso de la República está integrado por una bancada mayoritaria que apoya al gobierno del actual presidente de la República. Es así como en su primer periodo constitucional (2002-2006) aprobó todas sus iniciativas de reforma constitucional (siete). Asimismo, el presidente 
promovió un fallido referendo constitucional que intentaba modificar de manera profunda la Constitución de 1991, pero que no logró la mayoría aprobatoria del pueblo, aunque sí su fase previa consistente en una ley en donde el Congreso convocó a la consulta. Una de las reformas constitucionales aprobadas por el Congreso es el acto legislativo 02 del 2004, que modificó la Constitución para permitir la relección presidencial inmediata, hasta entonces prohibida expresamente por la carta política de 1991.

Durante 2005, la sociedad colombiana permaneció expectante ante la decisión de la Corte Constitucional sobre la reforma que permitía la relección presidencial. Las encuestas señalaban más de un $80 \%$ de aprobación popular al entonces mandatario, que aspiraba a una eventual reelección. Sus partidarios, así como un amplio sector de la sociedad clamaban por la constitucionalidad -incluso algunos realizaron marchas públicas de respaldo a la reforma- De otro lado, los opositores al gobierno confiaban en que la relección era inconstitucional. Pero ¿por qué todos se referían a la inconstitucionalidad de una reforma de la Constitución? ¿Acaso ésta no pretende modificar la Constitución? El asunto no es tan sencillo. Veamos: el artículo 379 de la Constitución colombiana señala "los actos legislativos, la convocatoria a referendo, la consulta popular o el acto de convocación de la Asamblea Constituyente, sólo podrán ser declarados inconstitucionales cuando se violen los requisitos establecidos en este título" y el artículo 241, sobre las funciones de la Corte Constitucional, en su numeral 1 establece que a ella corresponderá: "Decidir sobre las demandas de inconstitucionalidad que promuevan los ciudadanos contra los actos reformatorios de la Constitución, cualquiera que sea su origen, sólo por vicios de procedimiento en su formación". Una interpretación literal llevaría a pensar que sólo se examinaría el trámite surtido para aprobar la reforma: es decir, gobiernistas y opositores tendrían como centro de discusión, si el procedimiento se cumplió o no. Sin embargo, el debate era mucho más complejo: la Corte había fijado un precedente polémico en su sentencia C-551 de 2003. Según éste, el control de los actos reformatorios de la Constitución también incluía juzgar si se habían configurado vicios de competencia que vulneraran el procedimiento de reforma. La Corte había dicho:

[La] proyección de los problemas de competencia, tanto sobre los vicios de procedimiento como sobre los vicios de contenido material... es un presu- 
puesto ineludible del procedimiento, a tal punto que el procedimiento está siempre viciado si el órgano que dicta un acto jurídico carece de competencia, por más de que su actuación, en lo que al trámite se refiere, haya sido impecable...

Cuando la Constitución adjudica a la Corte el control de los vicios de procedimiento en la formación de una reforma constitucional... no sólo le atribuye el conocimiento de la regularidad del trámite como tal, sino que también le confiere competencia para que examine si el Constituyente derivado, al ejercer el poder de reforma, incurrió o no en un vicio de competencia. ${ }^{34}$

El precedente fijado significa que el Congreso tiene la facultad para reformar la Constitución pero no para sustituirla. Después de este fallo la Corte Constitucional ha resuelto 22 demandas ciudadanas en contra de actos legislativos. En nueve oportunidades los demandantes han formulado cargos por sustitución de la Constitución y en ningún caso los ha concedido. ${ }^{35}$ En octubre de 2005 la Corte decidió la constitucionalidad del acto legislativo 2 de 2004 y determinó que el Congreso actuó dentro del margen constitucional al aprobar la reforma que permite la relección presidencial.

Como se puede apreciar, el reformismo constitucional, constante en el constitucionalismo colombiano, se ha acentuado en los últimos cuatro años. Aunque la Corte Constitucional ha desarrollado una jurisprudencia que intenta limitar el poder de reforma constitucional por el Congreso, en la práctica ésta no ha significado una barrera para que las mayorías políticas modifiquen la carta política.

34 Corte Constitucional, sentencia C-551 de 2003, M. P. Eduardo Montealegre Lynett.

35 El "test de sustitución de la Constitución" tiene éstas características: es un juicio sobre la competencia del órgano que reforma; se requiere enunciar los aspectos que definen la identidad de la Constitución que se supone han sido sustituidos; debe establecerse el alcance jurídico respecto a los elementos definitorios de la Constitución; se deben contrastar las premisas con el criterio de juzgamiento que la Corte señala, es decir verificar si la reforma remplaza un elemento definitorio que identifica la Constitución por otro integralmente diferente. El desarrollo de los pasos de este juicio de sustitución es aún incipiente en la jurisprudencia constitucional. Puede interpretarse que la Corte Constitucional conserva un margen de discreción para interpretar algunos de los elementos de este test con el fin de evitar la petrificación del orden constitucional, pero también puede ser visto como un instrumento peligroso en manos de una juez constitucional activista, que por esta vía podría convertirse en constituyente; $c f r$. Cajas, Mario, "Reforma constitucional: límites de la Corte al Congreso", Precedente, Anuario Jurídico 2004, Cali, 2005. 


\title{
3. El minimalismo judicial de la Corte Constitucional
}

\author{
Una de las más polémicas reformas constitucionales aprobadas por el \\ Congreso de Colombia en los últimos años fue el "estatuto antiterrorista" \\ contenido en el Acto Legislativo 2 de 2003, ${ }^{36}$ que generó gran controver-
}

36 La reforma tenía, en lo relevante, este contenido: “Artículo 1o. El artículo 15 de la Constitución Política quedará así: 'Artículo 15. Todas las personas tienen derecho a su intimidad personal y familiar y a su buen nombre, y el Estado debe respetarlos y hacerlos respetar. De igual modo, tienen derecho a conocer, actualizar y rectificar las informaciones que se hayan recogido sobre ellas en los bancos de datos y en archivos de entidades públicas y privadas. En la recolección, tratamiento y circulación de datos se respetarán la libertad y demás garantías consagradas en la Constitución. La correspondencia y demás formas de comunicación privada son inviolables. Sólo pueden ser interceptados o registrados mediante orden judicial, en los casos y con las formalidades que establezca la ley. Con el fin de prevenir la comisión de actos terroristas, una ley estatutaria reglamentará la forma y condiciones en que las autoridades que ella señale, con fundamento en serios motivos, puedan interceptar o registrar la correspondencia y demás formas de comunicación privada, sin previa orden judicial, con aviso inmediato a la Procuraduría General de la Nación y control judicial posterior dentro de las treinta y seis (36) horas siguientes. Al iniciar cada periodo de sesiones el gobierno rendirá informe al Congreso sobre el uso que se haya hecho de esta facultad. Los funcionarios que abusen de las medidas a que se refiere este artículo incurrirán en falta gravísima, sin perjuicio de las demás responsabilidades a que hubiere lugar. Para efectos tributarios judiciales y para los casos de inspección, vigilancia e intervención del Estado, podrá exigirse la presentación de libros de contabilidad y demás documentos privados, en los términos que señale la ley'. Artículo 2o. El artículo 24 de la Constitución Política quedará así: 'Artículo 24. Todo colombiano, con las limitaciones que establezca la ley, tiene derecho a circular libremente por el territorio nacional, a entrar y salir de él, y a permanecer y residenciarse en Colombia. El Gobierno Nacional podrá establecer la obligación de llevar un informe de residencia de los habitantes del territorio nacional, de conformidad con la ley estatutaria que se expida para el efecto'. Artículo 3o. El artículo 28 de la Constitución Política quedará así: 'Artículo 28. Toda persona es libre. Nadie puede ser molestado en su persona o familia, ni reducido a prisión o arresto, ni detenido, ni su domicilio registrado, sino en virtud de mandamiento escrito de autoridad judicial competente, con las formalidades legales y por motivo previamente definido en la ley. La persona detenida preventivamente será puesta a disposición del juez competente dentro de las treinta y seis (36) horas siguientes, para que este adopte la decisión correspondiente en el término que establezca la ley. En ningún caso podrá haber detención, prisión ni arresto por deudas, ni penas y medidas de seguridad imprescriptibles. Una ley estatutaria reglamentará la forma en que, sin previa orden judicial, las autoridades que ella señale puedan realizar detenciones, allanamientos y registros domiciliarios, con aviso inmediato a la Procuraduría General de la Nación y control judicial posterior dentro de las treinta y seis (36) horas siguientes, siempre que existan serios mo- 
sia nacional: algunos abogaban por su constitucionalidad, fundados en la necesidad de dotar de herramientas jurídicas al gobierno nacional para la lucha antiterrorista y así preservar el orden público, al tiempo que se garantizaban los derechos. ${ }^{37} \mathrm{Se}$ trataba de contar con instrumentos idóneos para responder a la principal política que permitió elegir al actual presidente de la República: la seguridad democrática para derrotar a los grupos alzados en armas (insurgentes y paramilitares). De otra parte, varios sectores, incluso, organismos internacionales de protección de los derechos humanos, consideraban que la reforma afectaba ostensiblemente los derechos fundamentales y las libertades públicas consagradas en la Constitución de 2004 (en adelante la C-816).

La Sala Plena de la Corte Constitucional, dentro del juicio de constitucionalidad al "estatuto antiterrorista", inició la discusión sobre uno de los cargos: aquel que acusaba a la reforma de haber sustituido la Constitución y por lo tanto de una extralimitación de la competencia del Congreso. Sin embargo, los nueve magistrados que componen la Sala no lograron un acuerdo para tomar la decisión (que requería cinco votos)

tivos para prevenir la comisión de actos terroristas. Al iniciar cada periodo de sesiones el gobierno rendirá informe al Congreso sobre el uso que se haya hecho de esta facultad. Los funcionarios que abusen de las medidas a que se refiere este artículo incurrirán en falta gravísima, sin perjuicio de las demás responsabilidades a que hubiere lugar". “Artículo 4o. El artículo 250 de la Constitución Política tendrá un parágrafo del siguiente tenor: 'Parágrafo 2o. Para combatir el terrorismo y los delitos contra la seguridad pública, y en aquellos sitios del territorio nacional donde no exista una autoridad judicial a la que se pueda acudir en forma inmediata o donde el acceso de los funcionarios ordinarios de policía judicial no sea posible por excepcionales circunstancias de orden público, la Fiscalía General de la Nación conformará unidades especiales de Policía Judicial con miembros de las Fuerzas Militares, las cuales estarán bajo su dirección y coordinación. Para el desarrollo de las labores propias de esta función, los miembros de la unidad pertenecientes a las fuerzas militares se regirán, sin excepción, por los mismos principios de responsabilidad que los demás miembros de la unidad especial'. Artículo 5o. Vigencia. Las adiciones a la Constitución Política efectuadas mediante el presente acto legislativo empezarán a regir a partir de su promulgación... Los actos terroristas a que se refiere este Proyecto serán los definidos como tales por la legislación penal vigente".

37 Como demandantes, actuaron en diferentes acciones públicas de inconstitucionalidad contra la misma reforma, Wilson Borja, representante a la Cámara por el Polo Democrático Alternativo, partido opositor de izquierda y minoría política en el Congreso colombiano, y Gustavo Gallón de la Comisión Andina de Juristas. Más de 130 ciudadanos intervinieron en el proceso ante la Corte Constitucional para apoyar la inconstitucionalidad de la reforma. 
Entonces, procedieron a analizar los vicios de trámite, el otro cargo en contra de la reforma. Al respecto, dijo la Corte:

...en muchas situaciones, es prudente que los jueces se pronuncien únicamente sobre aquellos aspectos que sean necesarios para tomar la decisión del caso, sin entrar a analizar otros temas, sobre todo si se trata de asuntos polémicos en torno a los cuales sea difícil alcanzar un acuerdo... en el presente caso, la Corte comenzó por una discusión de los eventuales vicios de competencia planteados por las demandas, pero no fue posible llegar a un acuerdo que permitiera, dentro de un término razonable, tomar una decisión al respecto. La Corte examinó entonces los fundamentos de cada una de las acusaciones por vicios de trámite... y consideró que debía entrar en el análisis detallado de uno de estos cargos, a saber el relacionado con la presunta irregularidad presentada al aprobar el informe de ponencia previo a la votación del articulado del proyecto de acto legislativo en el sexto debate de la segunda vuelta. La Corte consideró que ese cargo podía prosperar... y haría innecesario el estudio sistemático y detallado de las otras acusaciones... esta opción metodológica de entrar a analizar y decidir directamente los cargos que tienen mayor potencialidad de prosperar, aun cuando pueda parecer más lógico estudiar otra acusación previamente, no es una invención de esta sentencia ni de esta Corte. ${ }^{38}$

Según la Corte, la opción metodológica que toma en la C-816 también ha sido usada por otros tribunales en el mundo, como el francés, pero además afirma que la propia Corte ha hecho uso de ella en diversas sentencias anteriores. Sin emabargo, una revisión de las sentencias C-87/ 2001, C- 147 y C-839 del 2003 y la C-573/2004 que la Corte cita como ejemplo de su minimalismo, no resultan completamente ajustadas: ${ }^{39}$ la

38 Corte Constitucional, sentencia C-816 de 2004, M. P. Jaime Córdoba Triviño y Rodrigo Uprimny Yepes. Fundamentos jurídicos números 9 y 10.

39 "La Sentencia C-573 de 2004, M. P. Rodrigo Uprimny Yepes, que declaró inexequible el inciso 12 del numeral 2o. artículo 8o. de la Ley 812 de 2003, por violar la regla de unidad de materia; la Corte se abstuvo entonces de estudiar los otros cargos de la demanda, pues la norma sería en todo caso retirada del ordenamiento. Véase igualmente la sentencia C-839 de 2003, M. P. Jaime Córdoba Triviño, que declaró la inexequibilidad del artículo 22 de la Ley 797/03, que disponía un descuento del 50\% en el cobro de copagos y cuotas moderadoras de los pensionados que devengaran mesadas de hasta tres salarios mínimos. La demanda presentaba, esencialmente, cargos por violación del principio de consecutividad y del principio a la igualdad. La Corte sólo estudió la primera censura y con base en ella declaró la inexequibilidad del precepto. La sentencia C-147 de 2003, 
magnitud jurídica y política de una reforma constitucional como la señalada, su capacidad de generar divergencias en el seno de la Corte, así como por tratarse de la prueba de fuego al recién inaugurado precedente del juicio de sustitución constitucional (fijado en 2003), no se asemeja a los juicios contra las reformas de tipo legal a que se refieren las sentencias mencionadas por la Corte. Esas sentencias no aluden a teorías, obras o prácticas judiciales minimalistas y su única similitud con el minimalismo de la C-816 consiste en que también se adopta la metodología de decidir un cargo de "estricta forma" en el trámite legislativo, y no uno de "fondo". 40

En la C-816, la Corte admite explícitamente que la opción metodológica escogida se conoce como minimalismo judicial y es defendida por el constitucionalista estadounidense Cass R. Sunstein, quien es precisamente citado en el fallo. ${ }^{41} \mathrm{La}$ Corte es minimalista porque evade el análisis y la decisión acerca de la presunta sustitución de la Constitución por parte de una reforma, considerada por un amplio sector de la comunidad jurí-

M. P. Rodrigo Escobar Gil, que declaró la inexequibilidad de algunos apartados de la Ley 788 de 2002, referentes a los impuestos aplicables a los juegos de suerte y azar, con base en la comprobación de irregularidades en el trámite legislativo, consistentes en la violación de los principios de consecutividad e identidad. En consecuencia, la Corte no analizó los cargos por vicios de fondo, relativos a la afectación de los principios de seguridad jurídica y buena fe respecto al pago del tributo. Igualmente la sentencia C-087 de 2001, M. P. Cristina Pardo Schlesinger, que declaró la inexequibilidad de algunas disposiciones de un proyecto de ley, que modificaba la Ley 142/94, en lo relativo al uso de Gas Licuado de Petróleo en automotores, proyecto que había sido objetado por el gobierno. La objeción prosperó por violación del principio de unidad materia, por lo que la Corte no analizó los demás cargos que habían sido planteados por el Ejecutivo...”, $c f r$. Sentencia C-816 de 2004, cit., nota 2.

40 En las sentencias referidas no aparece registrada la presunta "división" de los magistrados de la Corte sobre temas sensibles o de difícil consenso, que haya hecho a la Corte optar por decidir sobre un cargo de inconstitucionalidad con preferencia sobre otro.

41 La Corte Constitucional cita a Cass Sunstein en otras tres sentencias: en la C-1147 de 2001, Manuel José Cepeda Espinosa se refiere al libro Republica.com, 2001, y en la sentencia C-150 de 2003, refiere la obra After the Rights Revolution, Reconceiving the Regulatory State (1990) y en la sentencia C-355 de 2006, Clara I. Vargas y Jaime Araujo, que despenalizó el aborto en algunas circunstancias, aparece citado "Pornography, Abortion, Surrogacy", del libro The Partial Constitution, Cambridge, Harvard University Press. El magistrado Rodrigo Uprimny también alude al minimalismo de Sunstein en su libro Legal Reasoning and Political Conflict (1996) en la aclaración de su voto a la sentencia C-572 de 2004 de la Corte Constitucional. 
dica como atentatoria de lo derechos fundamentales garantizados por la Constitución de 1991. La Corte declaró la inexequibilidad del Acto Legislativo 02 de diciembre de 2003 porque en su trámite de aprobación se desconoció el procedimiento agravado propio de la reforma constitucional y se distorsionó la voluntad democrática de las cámaras, pues se ignoró una votación en donde la reforma no alcanzaba la mayoría absoluta requerida. ${ }^{42}$

La C-816 únicamente toma un aspecto del minimalismo judicial, el cual es la carencia de acuerdo sobre un tema que evita ser tomado en cuenta, para debatir otro que sí era susceptible de un "acuerdo incompleto". Como el estatuto había generado una profunda división y discusión pública: de un lado, sobre los límites a la seguridad y la defensa del orden público; y de otro, la necesidad de proteger derechos humanos en un país con un largo, complejo e intenso conflicto armado interno, la Corte tomó una decisión, que podría decirse defiende el "corazón" o núcleo de la Constitución: los derechos fundamentales, pero no se comprometió con la definición de lo que significa "sustituir" la Constitución. La sentencia garantizó el margen de acción del Congreso para reformar la Constitución y también evidenció el escaso consenso existente en la Corte con respecto a la sustitución constitucional.

Más allá de la sentencia mencionada, hay otros aspectos de la justicia constitucional colombiana que también pueden evidenciar espacios para prácticas minimalistas, tanto en la revisión de fallos de tutela como en el juicio de constitucionalidad abstracto: en primer lugar, distinguiendo las posiciones diferentes que ocupa cada tribunal en sus respectivas jurisdicciones, se podría afirmar que existe una cierta similitud entre la discrecionalidad del certiorari jurisdiction o recurso de certiorari de la Corte Suprema de los Estados Unidos ${ }^{43}$ y la revisión de los fallos de tutela por la Corte Constitucional colombiana. El certiorari jurisdiction americano le permite a la Corte Suprema rechazar o no conocer un caso por diversas

42 Corte Constitucional, sentencia C-816 de 2004, fundamento jurídico núm. 144.

43 "A través del writ of certiorari, la Corte elige con gran libertad el tipo de asuntos que requiere su atención. Con dicha elección el Tribunal decide si participa o no en el proceso de elaboración de la doctrina judicial vinculante. La capacidad fáctica que tiene el Tribunal para atender un número limitado de asuntos al año hace que no pueda pronunciarse sobre todas las cuestiones de derecho federal que se discuten en los tribunales federales y estatales", cfr. Magaloni K., Ana Laura, El precedente constitucional en el sistema judicial norteamericano, Madrid, McGraw-Hill, 2001, pp. 172 y 173. 
razones, como la falta de importancia del asunto a tratar, el carácter inusual de los hechos particulares que éste reúne, o el carácter controversial del problema. ${ }^{44}$ En Colombia, la Corte Constitucional también goza de amplia discrecionalidad cuando selecciona fallos de tutela para su revisión. Esta selección de los fallos que finalmente revisa la Corte, al igual que el certiorari americano, no requiere ser justificada. En el caso de la Corte Suprema se trata de un espacio para el minimalismo judicial, pero también puede serlo en el citado caso de la Corte Constitucional. ${ }^{45}$

En Colombia, la Corte tiene otros espacios para la discrecionalidad, que pueden permitir el minimalismo frente a asuntos polémicos que deseen evitarse: se trata de la acción pública de inconstitucionalidad, en donde una de las razones para que se rechace la demanda consiste en que la Corte encuentra que ha operado la cosa juzgada absoluta respecto del cargo formulado y por lo tanto decide no adelantar el juicio de constitucionalidad. Pero la Corte conserva un importante grado de discrecionalidad con respecto a la definición de la cosa juzgada relativa, que consistiría en que la Corte se pronunció con anterioridad sobre la norma demandada aunque con respecto a un cargo diferente al que ahora se formula. En este último caso, la Corte sí adelanta el juicio de constitucionalidad. 46

44 Véase Stone, Geofrey et al., Constitutional Law, cit., nota 18, pp. 160-162.

45 Para un completo estudio sobre la revisión de tutelas por la Corte Constitucional y los retos que ésta enfrenta, véase Ossa Santamaría, Julio Andrés, "El proceso de selección de tutelas en la Corte Constitucional: una lucha entre la igualdad y la seguridad jurídica", en Bonilla, Daniel e Iturralde, Manuel (eds.), Hacia un nuevo derecho constitucional, Bogotá, Facultad de Derecho, Universidad de los Andes, 2005, pp. 385-410.

46 En una reciente sentencia, la C-155 de 2007 ( M. P. Álvaro Tafur Gálvis), la Corte recuerda cómo su jurisprudencia ha diferenciado el carácter absoluto o relativo de la cosa juzgada en el control abstracto de constitucionalidad. En el primer caso, la disposición acusada ha comprendido todo el ordenamiento constitucional. En el segundo, ésta se ha limitado a una parte específica del mismo. Sólo en este último caso queda abierta la posibilidad de plantear una nueva controversia, pero únicamente por razones o cargos distintos a los analizados en el proceso inicial. Para determinar una u otra condición, la Corte reitera que existe una presunción de control integral, es decir, "debe entenderse que toda sentencia de constitucionalidad hace tránsito a cosa juzgada absoluta, salvo que la propia Corporación, bien de manera explícita en la parte resolutiva, o bien de manera implícita en la parte motiva, restrinja el alcance de su decisión a los cargos analizados en la sentencia”. Sólo si existe cosa juzgada relativa explícita (si se consigna expresamente en la parte resolutiva del fallo) o implícita (si se infiere clara e inequívocamente del análisis constitucional hecho en la parte motiva del respectivo fallo), se analiza de nuevo su 


\section{CONSIDERACIONES FINALES}

La obra del profesor Sunstein es un valioso aporte a la teoría jurídica y al derecho constitucional. Su metodología parte de la observación real sobre cómo los jueces deciden los casos, a través de un riguroso estudio de los precedentes constitucionales de la Corte Suprema de los Estados Unidos. Su formulación teórica, fiel a la tradición constitucional y jurídica norteamericana, parte del derecho judicial. Esto, por sí solo, significa un importante referente para la investigación sobre el derecho judicial y el constitucionalismo. De otro lado, el minimalismo judicial se muestra como una herramienta que podría ser útil para la adjudicación, hoy, cuando casi todas las cartas políticas contienen normas de textura abierta sobre materias que provocan profundos desacuerdos teóricos y disensos sociales.

En el caso del estatuto antiterrorista, cuya inconstitucionalidad fue resuelta en la sentencia C-816 de 2004, resulta cómodo defender la postura minimalista de la Corte Constitucional, pues la decisión evitó poner en riesgo los derechos fundamentales y por lo tanto podría catalogarse como progresista. El fallo también envió un mensaje político al Ejecutivo y al Congreso, acerca de la inconveniencia de este tipo de reformas: a la fecha no se tiene noticia de que el gobierno nacional haya radicado ante el Congreso una iniciativa similar, aunque jurídicamente pueda hacerlo pues la decisión de la Corte Constitucional se refirió únicamente a aspec-

constitucionalidad, cuando se formulan cargos distintos en donde se aprecie una controversia sustancialmente diferente a la que ya fue objeto de estudio por la Corte. De igual modo, en la sentencia C-1189 de 2005, M. P. Humberto Sierra Porto, la Corte recuerda la evolución de su línea jurisprudencial, haciendo referencia a las sentencias C-447 de 1997, C-774 de 2001,C-228 de 2002, C-665 de 2005, entre otras, y concluye "La cosa juzgada material tiene lugar únicamente cuando concurren las siguientes condiciones: (i) Que exista una sentencia de constitucionalidad sobre el mismo precepto normativo e incluido en el mismo cuerpo normativo, respecto del cual se solicita estudio posterior (identidad formal). (ii) Que exista identidad entre los cargos que fundamentaron el juicio de constitucionalidad que dio lugar a la sentencia proferida por esta Corporación y aquellos que sustentan la nueva solicitud de estudio. (iii) Que no se hayan producido cambios económicos, sociales, culturales, políticos e, incluso, ideológicos sustancialmente significativos que hagan insostenible, a la luz de la Constitución, el pronunciamiento anterior. Esto es, que se presente una identidad en el contexto fáctico y normativo entre el momento en que la Corte hizo su anterior pronunciamiento y el momento en que se solicita el nuevo análisis". 
tos de trámite en el Congreso y por lo tanto su inconstitucionalidad no hizo tránsito a cosa juzgada respecto del contenido material de la reforma. Esto también podría favorecer la democracia deliberativa.

De otro lado, el minimalismo y su transplante a América Latina, como teoría o como práctica, debe analizarse con rigor. Habría que detenerse a evaluar factores característicos de la región como el déficit democrático y la pasividad de muchos de sus gobiernos en la lucha contra la pobreza: en el caso colombiano debería sumarse el grave conflicto armado, un Congreso de la República cuyo balance en materia de desarrollo de la Constitución es pobre y en donde la Corte Constitucional se ha erigido en el principal — por no decir único- garante de los derechos. ${ }^{47}$ En este contexto es necesario considerar los beneficios de practicar únicamente el minimalismo judicial, a la manera como Sunstein señala. De igual modo, es oportuno preguntarse si es posible comparar el minimalismo de la Corte Suprema de Estados Unidos, inserta en un sistema político y jurídico más robusto que el colombiano, y con una larga tradición del judicial review y de la protección judicial de los derechos. En principio, no parecería claro que en Colombia la Corte Constitucional únicamente haga uso de la opción minimalista, excluyendo otras opciones en la adjudicación, pues se trata de un país en donde las mayorías en el Congreso han reformado la Constitución 17 veces en 15 años. El minimalismo, como única opción metodológica, podría frenar la evolución judicial de la protección de los derechos, y en última instancia, la consolidación de la Constitución política de 1991.48

Aún es necesario continuar investigaciones que ayuden a establecer con mayor claridad qué tanto la Corte Constitucional ha usado el minimalismo, más allá de que esta práctica haya sido explícita en sentencias como la C-816 de 2004, aquí analizada.

47 La inactividad constitucional del Congreso es evidente. A manera de ejemplos, después de 15 años de haber entrado en vigencia la Constitución, aún no se aprueban la ley estatutaria de los derechos fundamentales el estatuto del trabajo que la carta política ordena. Mientas tanto, el juez constitucional ha producido una jurisprudencia progresista sobre ambos temas, a través de la revisión de los fallos de tutela e incluso en las sentencias de constitucionalidad abstracta.

48 Reitero lo dicho en la nota 10, supra. 


\section{BIBLIOGRAFÍA}

BERNAL PUlido, Carlos, El derecho de los derechos, Bogotá, Universidad Externado de Colombia, 2005.

CAJAS SARRIÁ, Mario, "Reforma constitucional: límites de la Corte al Congreso", Precedente, Anuario Jurídico 2004, Cali, 2005.

DWORKIN, Ronald, Law's Empire, Harvard University Press, 1986.

-, Taking Rights Seriously, Harvard University Press, 1977.

LAMPREA MONTEALEGRE, Everaldo, "El test de razonabilidad en la jurisprudencia de la Corte Constitucional durante el año 2001", Anuario de Derecho Constitucional: análisis de jurisprudencia de la Corte Constitucional, Bogotá, Universidad Externado de Colombia, 2003.

, "Derechos fundamentales y consecuencias económicas", Revista de Economía Institucional, Bogotá, vol. 8, núm. 12, primer semestre de 2006.

__ "Los servicios públicos domiciliarios y el Estado regulador", Precedente, Anuario Jurídico, Cali, 2004.

LÓPEZ MEDINA, Diego Eduardo, El derecho de los jueces, 2a. ed., Bogotá, Legis, 2006.

MACCORMICK, Neil y SUMMERS, Robert (eds.), Interpreting Precedents. A comparative Study, USA, UK, Ashgate-Darthmouth, 1997.

MAGALONI, Ana Laura, El precedente constitucional en el sistema judicial norteamericano, Madrid, McGraw-Hill, 2001.

OSSA SANTAMARÍA, Julio Andrés, "El proceso de selección de tutelas en la Corte Constitucional: una lucha entre la igualdad y la seguridad jurídica", en Bonilla, Daniel e ITURRALDE, Manuel (eds.), Hacia un nuevo derecho constitucional, Bogotá, Facultad de Derecho, Universidad de los Andes, 2005.

Stone, Geofrey et al., Constitutional Law, 5a. ed., Nueva York, Aspen, 2005.

SunsteIn, Cass, R., "Incompletely Theorized Agreements", Harvard Law Review, vol. 108, 1995.

—, Legal Reasoning and Political Conflict, Oxford, Oxford University Press, 1996.

- One Case at a Time: Judicial Minimalism at the Supreme Court, 2a. ed., Cambridge, Harvard University Press, 1999.

, Radicals in Robes: Why Extreme Right-Whing are wrong for America, Cambridge, Basic Books, 2005. 
TRIBE, Lawrence, American Constitucional Law, 3a. ed., Nueva York, vol. 1, Foundation Press, 2000.

TUSHNET, Mark, "Judicial Review of Legislation", en CANE, Peter et al., The Oxford Handbook of Legal Studies, Nueva York, Oxford University Press, 2003.

UPRIMNY, Rodrigo y FUENTES, Adriana, Libertad de Prensa y derechos fundamentales: análisis de la jurisprudencia constitucional en Colombia (1992-2005), Bogotá, Dejusticia-Andiarios-Fundación Konrad Adenauer, 2006.

Bases de datos en línea y páginas de Internet

LEXBASE, jurisprudencia de la Corte Constitucional 1992- 2007, citas referidas a Cass Sunstein.

NOTINET, jurisprudencia de la Corte Constitucional.

http://www.law.uchicago.edu/faculty/sunstein

http://philosophy.fas.nyu.edu/object/ronalddworkin

http:/ssrn.com/abstract_id $=880144$.Chttp:/ssrn.com/abstract_id $=880121$ 